\title{
POLYVINYLIDENE FLUORIDE BASED CATHODE PRODUCED BY ELECTROSPINNING OF THE LiFePO 4 BASED ELECTRODES
}

\author{
Auezkhan Kariphanovich Tashenov ${ }^{1}$, Filipp Sergeevich Napolskiy ${ }^{2}$, \\ Daniil Mikhailovich Itkis ${ }^{2}$, Victor Aleksandrovich Krivchenko ${ }^{2}$ \\ and Balken Talgatbekovna Kaparova ${ }^{3, *}$ \\ ${ }^{1}$ L.N. Gumilyov Eurasian National University, Nur-Sultan, 010008, Republic of Kazakhstan \\ ${ }^{2}$ Laboratory of Thin Films and Functional Materials, Engineering Center, Dubna State \\ University, 141980, Dubna, Moscow Region, Russian Federation, Skobeltsyn Institute of \\ Nuclear Physics, Lomonosov Moscow State University, Moscow, 119991, Russian Federation \\ ${ }^{3}$ Laboratory of Thin Films and Functional Materials, Engineering Center, Dubna State \\ University, 141980, Dubna, Moscow Region, Russian Federation, L.N. Gumilyov Eurasian \\ National University, Nur-Sultan, 010008, Republic of Kazakhstan \\ *E-mail: balkenkaparova@mail.ru
}

\begin{abstract}
The cathode is one of the key components in lithium batteries since its properties significantly affect the battery performance. Therefore, currently, the research in the field of cathode synthesis and modification is quite relevant. Among the various widely used strategies aimed at improving the electrochemical performance of batteries, the application of cathode surfaces is one of the extremely useful and widely used technologies. Electrospinning technology is one of the methods to produce porous electrodes out of a polymer solution by applying electrostatic forces to the solution. Polyvinylidene fluoride is one of the common polymer-binding agents in lithium-ion batteries. It is characterized by a useful combination of elasticity and mechanical strength that allows using it in the electrospinning method. The purpose of this work was the attempt to optimize the microstructure of the cathode coating by fabrication of the fiber cathode based on lithium-iron-phosphate with the help of the electrospinning technique using polyvinylidene fluoride.
\end{abstract}

Keywords: Electrospinning, Porosity, Polyvinylidene Fluoride, Electro-coated Surface, Fibril, Cathode.

(C) RASĀYAN. All rights reserved

\section{INTRODUCTION}

Lithium-ion batteries, due to their high energy density, good cyclability, flexible design, and good electrochemical abilities are used not only in portable devices but also in electric vehicles. ${ }^{1-5}$ Along with the anode, the cathode is one of the key components in the structure of lithium-ion batteries. The cathode coating consists of active material, a conductive additive, and a polymer binder. The active material is directly involved in the electrochemical reaction. Polymer binder and conductive additive, although are electrochemically inactive, along with the active material, are essential components in electrodes. Polymer binder provides adhesion of particles of the active material and the conductive additive to each other, as well as adhesion of the electrode coating to the current collector. The conductive additive promotes electronic conductivity between microparticles of the active material. ${ }^{6-8}$ The smooth operation of the battery depends on the optimal combination and location of all these components in the structure of the electrode film. The architecture of the electrode coating directly depends on the technological processes used to fabricate electrode, such as wet mixing, applying the coating, and drying of the prepared suspension..$^{9,10}$ In most cases, a common method of applying an electrode coating is a spread method, such for example, bladecoating. ${ }^{11-15}$ However, in recent years, the electrospinning method has attracted great attention of scientists

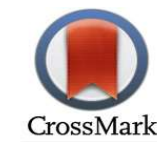


as one of the methods of applying an electrode coating on a substrate. The point is that the advantages of the electrode obtained by electrospinning are fibrillous structure, lower coating density, and large surface area, i.e. better contact of the all of the components, as well as greater coating porosity, which leads to less tortuosity of the pore structure, while this is a critical factor for improving ionic and electronic conductivity. ${ }^{16,17}$

The formation of fibrils using the electrospinning method occurs under the action of electrostatic forces applied on an electrically charged jet of the polymer solution. Obtaining uniform smooth fibrils directly depends on the type of polymer, its concentration in solution, and the volatility of the solvent. For example, when the percentage of polymer in the solvent is less than $7 \%$, the viscosity of the solution is quite low, and when spraying this suspension, the formation of small droplets instead of threads is quite possible. Conversely, if the percentage content of the polymer is more than $20-25 \%$, this leads to a change in the coating morphology from droplets to rough brittle fibrils. ${ }^{18,19}$ In addition to these parameters, the technological parameters of the electrospinning process, such as the electrical voltage at the nozzle, the distance between the electrodes, the speed of fibril formation, and air humidity are also important. The optimal combination of all noted parameters allows obtaining a homogeneous fibrillous coating. ${ }^{20-22}$

Currently, polyvinylidene fluoride (PVDF) is widely used as a polymer binder for the preparation of electrodes in commercially produced lithium-ion batteries. The possibility of producing electrodes using the electrospinning method has been demonstrated in several works, however using polyacrylonitrile $(\mathrm{PAN})^{23,24}$ or polyvinylpyrrolidone (PVP) as a polymer. ${ }^{25-30}$ Nevertheless, PVDF, as a widely used polymer binder, is characterized by chemical inertness, excellent thermal and mechanical properties with a good window of electrochemical stability. ${ }^{31,32}$ Moreover, PVDF-based fibrillous membranes demonstrate flexibility, plasticity, and other unique physical and chemical properties. ${ }^{33-35}$ The PVDF-based membranes are already used in sensors, mobile phones, biomedical devices, etc. ${ }^{36,37}$

In this article, it is proposed to produce membranes out of PVDF, as well as positive electrodes based on $\mathrm{LiFePO}_{4}$ for lithium-ion batteries using the electrospinning approach using PVDF as a polymer binder. It has been shown that PVDF films produced using electrospinning have a uniform fibrillous structure, while the use of a suspension containing $\mathrm{LiFePO}_{4}$ particles, carbon additive, and $\mathrm{PVDF}$ in a mixture of acetone with $\mathrm{N}, \mathrm{N}$-dimethylformamide allows obtaining electrode coatings in which the microparticles of the active material are in the fibrillous structure formed out of PVDF during electrospinning. At that, the microstructure of the resulting composite material provides both an effective ion transport to the $\mathrm{LiFePO}_{4}$ particles and a sufficient level of electrical conductivity when adding just $5 \mathrm{wt} . \%$ of carbon black that allows obtaining a large reversible electrochemical capacity at high specific discharge currents (up to $500 \mathrm{~mA} / \mathrm{g}$ ) compared to electrodes produced out of the same active material using blade-coating.

\section{EXPERIMENTAL}

\section{Materials and Reagents}

The N,N-dimethylformamide (DMF, 99\%, Russia), acetone (99\%, Russia), Timcal Super C45 carbon black $\left(45 \mathrm{~m}^{2} / \mathrm{g}\right.$, MTI Corporation), PVDF (Solef 5130, Solvay), lithium iron phosphate $\mathrm{LiFePO}_{4}(\mathrm{GN}-\mathrm{P} 198-\mathrm{H}$, Gelon LIB Group, the microstructure is shown in Fig.-1a) were used as original reactants and materials without additional purification.

\section{The Process of Preparing Suspensions}

Polyvinylidene fluoride films were prepared from a $10 \%$ viscous polymer solution by gradually dissolving PVDF for 2 hours at $60^{\circ} \mathrm{C}$ in a mixture of acetone with $\mathrm{N}$, N-dimethylformamide (volume ratio 1:2) followed by their deposition with the help of the electrospinning technique $\mathrm{LiFePO}_{4}$ suspension for electrospinning of the electrodes was performed with and without the addition of a conductive additive (carbon black). The $\mathrm{LiFePO}_{4}$ suspension with the conductive additive was prepared by gradual adding of carbon black to a $6 \%$ polymer solution into a mixture of acetone with $\mathrm{N}, \mathrm{N}$-dimethylformamide (volume ratio 1:2), and then $\mathrm{LiFePO}_{4}$ powder. To produce a viscous solution, $\mathrm{PVDF}$ was pre-dissolved at $60^{\circ} \mathrm{C}$ for two hours in a mixture of solvents. After adding lithium-iron phosphate, the suspension was stirred without heating for 12 hours to produce a homogeneous mass. The ratio of components in the resulting suspension 
RASĀYAN J. Chem.

Vol. 13 | No. 3 |1598-1605| July - September | 2020

was 86,9 , and $5 \%$ for $\mathrm{LiFePO}_{4}$, PVDF and carbon black, respectively. At that, $\mathrm{LiFePO}_{4}$ and $\mathrm{PVDF}$ ratios of 92 and $8 \%$, respectively, were used for electrospinning of the electrodes without adding carbon black (Table-1). This suspension was obtained by mixing LiFePO4 powder with an analogously prepared PVDF polymer solution.
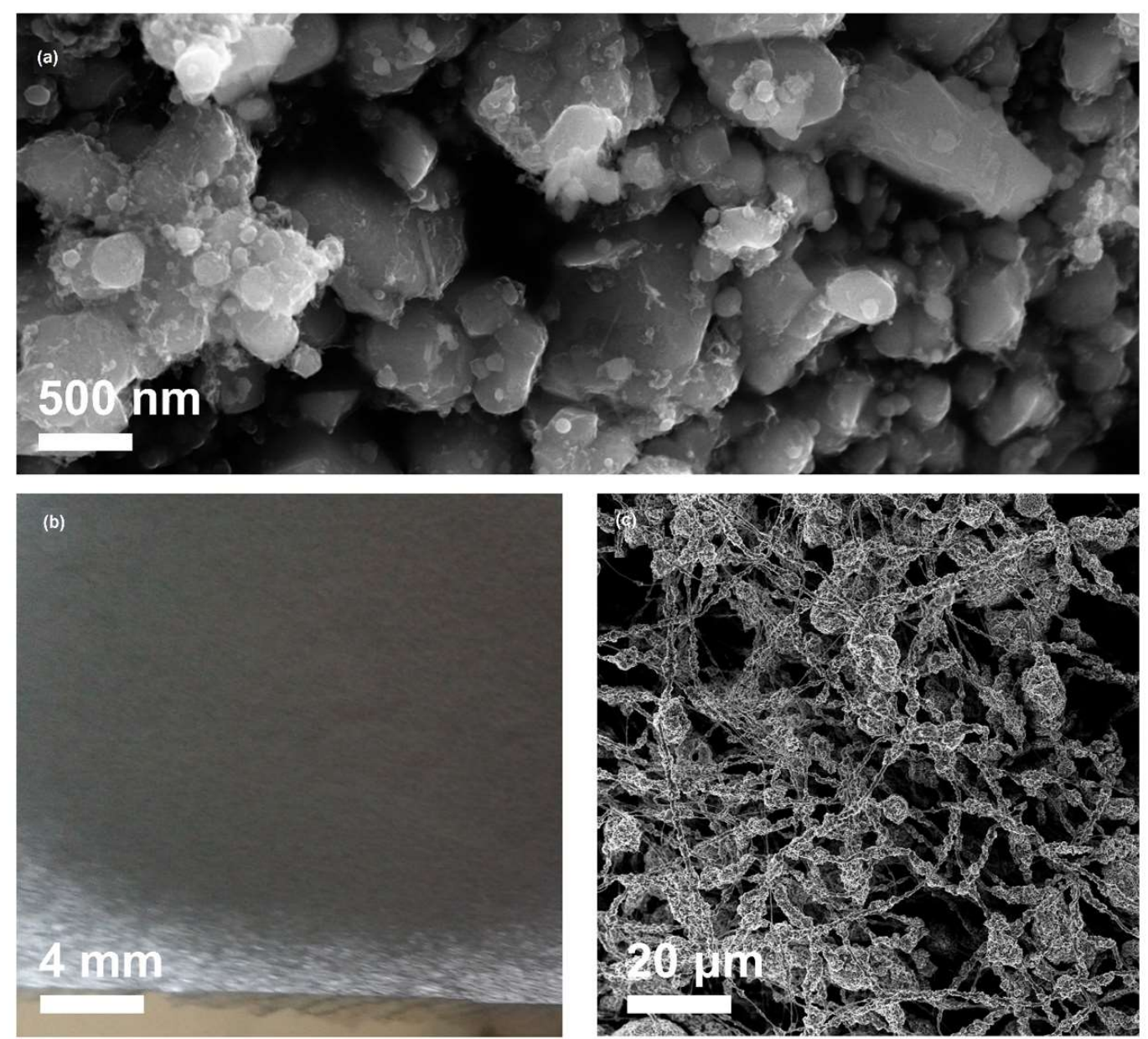

Fig.-1: The Microstructure of the used $\mathrm{LiFePO}_{4}$ Powder (a) as well as the Photo (b) and Electrode Microstructure (c) of the $\mathrm{LiFePO}_{4} / \mathrm{PVDF}$ Obtained by Electrospinning

Table-1: Composition of Suspensions

\begin{tabular}{l|c|c|c}
\hline Suspension Components & $\mathrm{LiFePO}_{4}, \%$ & PVDF, \% & Carbon Black, \% \\
\hline Without adding Carbon Black & 92 & 8 & \\
\hline With the addition of Carbon Black & 86 & 9 & 5 \\
\hline
\end{tabular}

The Process of Electrospinning

Electrospinning was performed using the Esprayer ES-2000S (Fuence Co., Ltd.). The deposition parameters for both films and electrodes were the same. The substrate temperature was maintained at $30^{\circ} \mathrm{C}$, the relative humidity of the air did not exceed $50 \%$. The distance between the nozzle $(0.51 \mathrm{~mm}$ diameter needle) and the substrate (carbon-coated aluminum foil, Gelon LIB Group) was $9 \mathrm{~cm}$, the voltage was $14 \mathrm{kV}$, and the feed rate of the deposition was $0.006 \mathrm{ml} / \mathrm{min}$. In the next step drying of the fibrillous coating was proceeded at $60^{\circ} \mathrm{C}$ in the air for 12 hours. After drying, the cut out of the sheet disc electrodes had a diameter of 15.5 $\mathrm{mm}$. The typical bulk loading of the resulting electrodes was $5-6 \mathrm{mg} / \mathrm{cm}^{2}$.

For comparison, the electrodes were prepared according to the traditional blade-coating technology out of the paste, in which the content of PVDF was $5 \mathrm{wt} . \%$ of dry matter, carbon black content was 5,10 , or 15 
RASĀYAN J. Chem.

Vol. 13 | No. 3 |1598-1605| July - September | 2020

wt. $\%$, and the content of $\mathrm{LiFePO}_{4}$ was 90,85 or $80 \mathrm{wt} . \%$, respectively. The pastes were prepared like the preparation of a suspension for electrospinning. Typical bulk loading, as for electrodes made by electrospinning, was $5-6 \mathrm{mg} / \mathrm{cm}^{2}$.

\section{Methods}

The obtained electrodes were tested in the CR2032 type coin cells with a negative electrode based on lithium titanate $\mathrm{Li}_{4} \mathrm{Ti}_{5} \mathrm{O}_{12}$ (Gelon LIB Group), whose bulk loading provided an excess capacity compared to the capacity of the studied electrodes. A glove box was used for assembling the cells in an argon medium with a moisture level of less than $0.1 \mathrm{ppm}$ and an oxygen concentration of less than $1.0 \mathrm{ppm}$. At that, $1 \mathrm{M}$ solution of lithium hexafluorophosphate LiPF6 in a mixture of ethylene carbonate, dimethyl carbonate, and diethyl carbonate is taken in a ratio of 1:1:1 by volume (Gelon LIB Group) was used as an electrolyte, while a membrane based on nonwoven polyethylene terephthalate with ceramic filler (Freudenberg Group) was used as a separator. Electrochemical measurements were carried out in galvanostatic mode under a voltage range of 1.5-2.2 $\mathrm{V}$ at specific currents of $10,50,125,250$, and $500 \mathrm{~mA} / \mathrm{g}$ per gram of active material. The voltages were recalculated about $\mathrm{Li}+/ \mathrm{Li}$ based on charge/discharge curves of negative electrodes obtained in lithium metal cells at the same current densities. Specific capacity was optimized and fixed per mass of the active material.

The morphology of the obtained cathodes was studied using a stereomicroscope with a digital camera equipped with a $7^{\mathrm{x}}$ lens and a $14^{\mathrm{x}}$ eyepiece (MBC-10, Russia). The microstructure of the fabricated polymer films and cathodes was studied using a scanning electron microscope (Carl Zeiss Supra 40-30-87).

\section{RESULTS AND DISCUSSION}

At the first stage of work, flexible films were produced out of PVDF using an electrospinning method. Such a film is quite elastic and has a uniformly smooth texture (Fig.-2a). The film microstructure indicates the fibrillous nature of the coating (Fig.-2b).
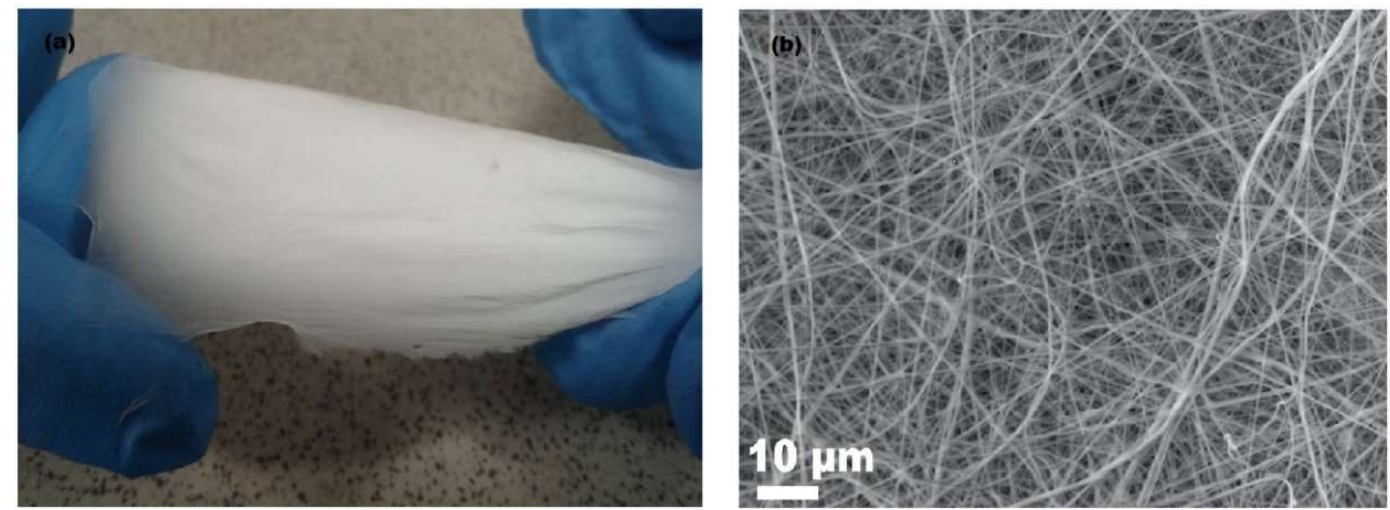

Fig.-2: Photo (a) and microstructure (b) of PVDF-based Film produced by the Electrospinning Method

At the second stage of the work, fibrillous positive electrodes based on $\mathrm{LiFePO}_{4}$ and $\mathrm{PVDF}$ were produced as a polymer binder (Fig. 1b). The proper selection of solvent and conditions of electrospinning allows obtaining homogeneous coatings. Figure-1c shows the characteristic microstructure of such a nonwoven electrode coating formed by randomly oriented fibrils. The $\mathrm{LiFePO}_{4}$ particles are embedded in the structure of polymer fibrils.

Electrochemical testing of the electrode fabricated without adding additional conductive components has shown that reversible intercalation/extraction of lithium is possible at low specific currents. As can be seen from Fig.-3a, the specific capacity of the material was approximately $140 \mathrm{mAh} / \mathrm{g}$ at a current rate of 10 $\mathrm{mA} / \mathrm{g}$ after 5 cell discharge/charge cycling. After the first cycles the coulombic efficiency, which was accompanied by the formation of a passivating film on the auxiliary electrode, approached $100 \%$. However, increasing the current density even to $50 \mathrm{~mA} / \mathrm{g}$, which corresponded to a speed of about $\mathrm{C} / 3$ led to a sharp drop in a capacity that was mainly due to the low electrical conductivity of $\mathrm{LiFePO}_{4}$. Commercially available iron-lithium phosphate powder used in the present work, according to the manufacturer, includes 
RASĀYAN J. Chem.

Vol. 13 | No. 3 |1598-1605| July - September | 2020

approximately $1.7 \pm 0.3 \%$ carbon in its composition, which is insufficient to ensure the required electrical conductivity of the material.
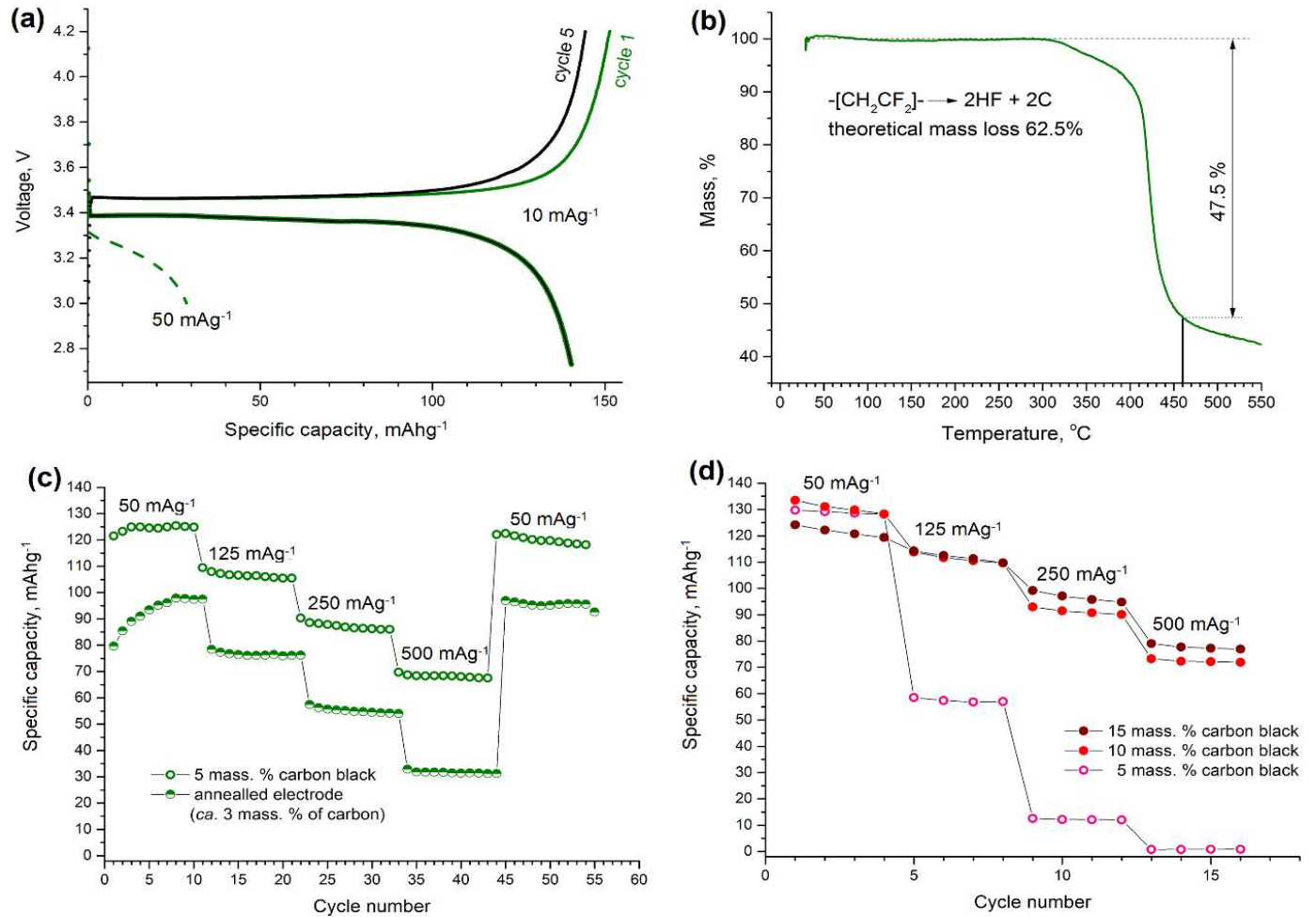

Fig.-3: (a) Discharge/charge curves for cells with a positive electrode based on $\mathrm{LiFePO}_{4} / \mathrm{PVDF}$ produced by the electrospinning method. Discharge/charge was carried out by currents of 10 and $50 \mathrm{~mA} / \mathrm{g}$ (per gram of active material). The voltage range was 2.7-4.2 V relative to $\mathrm{Li}+/ \mathrm{Li}$; (b) Mass loss curve for PVDF film produced by

electrospinning, recorded with heating equal to $5{ }^{\circ} \mathrm{C}$ per minute; (c) The capacity of the cells with positive electrodes obtained by electrospinning depending on the cycle number. Charge/discharge was carried out at different specific currents shown in the graph. The voltage range was $1.5-2.2 \mathrm{~V}$ relative to $\mathrm{Li}_{4} \mathrm{Ti}_{5} \mathrm{O}_{12} / \mathrm{Li}_{7} \mathrm{Ti}_{5} \mathrm{O}_{12}$. Open circles show the results for the electrode, which was formed from a suspension containing carbon black (in amount of 5 wt.\% of the mass of all solids); semi-dark circles show the results for the electrode coated without adding carbon black and annealed in argon at $460^{\circ} \mathrm{C}$; (d) Dependence of the discharge capacity of cells with positive electrodes obtained by blade-coating, and containing different amounts of carbon black (mass fraction of PVDF is $5 \mathrm{wt} . \%$ ).

The voltage range relative to $\mathrm{Li}_{4} \mathrm{Ti}_{5} \mathrm{O}_{12} / \mathrm{Li}_{7} \mathrm{Ti}_{5} \mathrm{O}_{12}$ was $1.5-2.2 \mathrm{~V}$, the specific currents are shown in the graph.

To enhance the electrical conductivity of the resulting cathode materials, two approaches were considered. The first approach consisted of annealing of the obtained electrode coatings in an inert atmosphere with partial carbonation of PVDF. As shown in ${ }^{38}$, the decomposition of PVDF proceeds with the release of HF and the formation of carbon. Thermogravimetric analysis was performed to determine the thermal treatment mode. The results obtained are shown in Fig.-3b. Calculations show that when electroformed films made of PVDF are heated in an argon atmosphere at a constant rate of $5^{\circ} \mathrm{C}$ per minute up to $460^{\circ} \mathrm{C}$, approximately $84 \%$ of the PVDF decomposes, which is accompanied by a $47.5 \%$ loss of sample mass. Based on these data, the composition of the electrodes initially containing $8 \%$ of PVDF after annealing is presented in Table-2.

Table-2: Composition of Annealed Electrodes

\begin{tabular}{c|c}
\hline Electrode Components & Wt.\% \\
\hline PVDF & 1 \\
\hline Carbon & 3 \\
\hline $\mathrm{LiFePO}_{4}$ & 96 \\
\hline
\end{tabular}


RASĀYAN J. Chem.

Vol. 13 | No. 3 |1598-1605| July - September | 2020

At that, $\mathrm{LiFePO}_{4}$ remains thermally stable at these temperatures ${ }^{39}$.

The decrease in the electrochemical capacity during cycling by different specific currents for electrodes obtained after thermal treatment is shown in Fig.-3c. It is seen that for an annealed electrode, the capacity reaches $100 \mathrm{mAh} / \mathrm{g}$ at a current density of $50 \mathrm{~mA}$ per gram of active material, and decreases markedly with a further increase in the discharge/charging current. Despite the marked improvement compared to the electrodes, which were not annealed, the increase of electrical conductivity after annealing is insufficient to obtain electrochemical characteristics comparable to those of electrodes manufactured by the conventional method (Fig.-3d). Thus, the partial thermal destruction of PVDF, which allows preserving the mechanical properties of the electrode and at the same time forming a small additional amount of electrically conductive carbon, cannot be used in practice.

Another method of introducing conductive carbon into the structure of the electrode composite was the addition of carbon black to the suspensions used for electrospinning. Figure-4a shows a cathode coating produced by electrospinning with the addition of $5 \mathrm{wt} . \%$ of carbon black. It is seen that the coating consists of fibrils and has a uniform texture. The microstructure of this coating confirms its porosity, though also indicates the presence of large $\mathrm{LiFePO}_{4}$ agglomerates with carbon black (Fig.-4b).
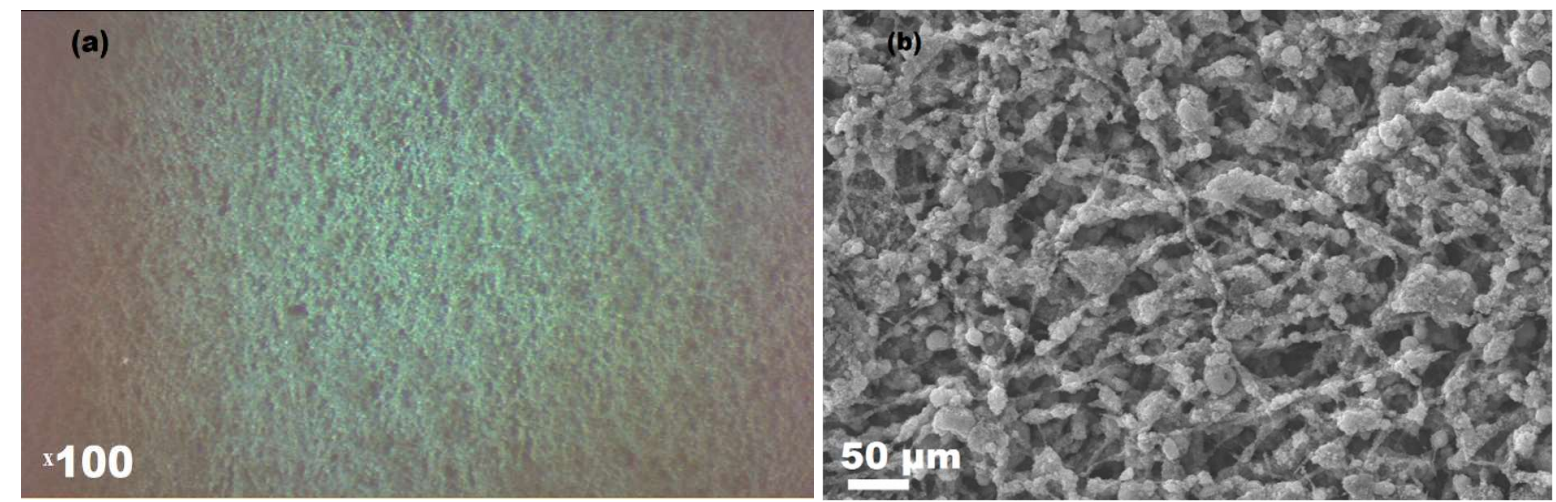

Fig.-4: Photo (a) and Microstructure of LiFePO4/PVDF-based Cathode Coating (b) produced by the Electrospinning Method with the Addition of 5 wt.\% of Carbon Black.

It turned out that fibrillous electrodes, produced by electrospinning and containing $5 \mathrm{wt} . \%$ of carbon black, at low specific current showed a capacity which was close to that for coatings obtained by blade-coating. At the same time, such electrode significantly benefits at high currents. From Fig. $3 \mathrm{~d}$ it can be seen that the capacity of the electrodes produced by blade-coating and containing just $5 \mathrm{wt} . \%$ of carbon black, sharply reduces by increasing the specific current up to $125 \mathrm{~mA} / \mathrm{g}$, while fibrillous electrodes with similar content of carbon black show better performance.

\section{CONCLUSION}

Thus, the authors have shown that the electrospinning method makes it possible to produce flexible and highly porous films and electrodes in which particles of the active material in the form of $\mathrm{LiFePO}_{4}$ and the electrically conductive additive in the form of carbon black are incorporated into polymer filaments of PVDF. Apparently, the microstructure of such electrodes provides better (compared to electrodes obtained by the traditional technology) electronic transport to the particles of the active material that makes it possible to reach better electrochemical characteristics at a reduced content of conductive carbon black.

\section{ACKNOWLEDGMENT}

The work was supported by a doctoral research scholarship from the Republic of Kazakhstan.The authors also wish to express their gratitude to S.Yu. Ryzhenkova for her assistance in the study of the microstructure of the fabricated electrodes.

\section{REFERENCES}

1. D. Zuo, G. Tian, X. Li, D. Chen and K. Shu, Journal of Alloys and Compounds, 706, 24(2017), DOI:10.1016/j.jallcom.2017.02.230

2. H. Meng and Y.-F. Li, Renewable and Sustainable Energy Reviews, 116, 109405(2019), DOI:10.1016/j.rser.2019.109405 
RASĀYAN J. Chem.

Vol. 13 | No. 3 |1598-1605| July - September | 2020

3. A. B. Haruna and K. I. Ozoemena, Current Opinion in Electrochemistry, 18, 16(2019), DOI: 10.1016/j.coelec.2019.08.005

4. C. M. Costa, Y.-H. Lee, J.-H. Kim, S.-Y. Lee and S. Lanceros-Méndez, Energy Storage Materials, 22, 346(2019), DOI: 10.1016/j.ensm.2019.07.024

5. Zh. Liao, Sh. Zhang, K. Li, G. Zhang and Th. G. Habetler, Journal of Power Sources, 436, 226879(2019), DOI:10.1016/j.jpowsour.2019.226879

6. G. Liu, H. Zheng, X. Song and V. S. Battaglia, Journal of The Electrochemical Society, 159, 214(2012), DOI: $10.1149 / 2.024203$ jes

7. D. Miranda, A. Gören, C. M. Costa, M. M. Silva, A. M. Almeida and S. Lanceros-Méndez, Energy, 172, 68(2019), DOI:10.1016/j.energy.2019.01.122

8. S. Jessl, D. Beesley, S. Engelke, Ch. J. Valentine, J. C. Stallard, N. Fleck, Sh. Ahmad, M. T. Cole and M. De Volder, Materials Science and Engineering: A, 735, 269(2018), DOI: $10.1016 /$ j.msea.2018.08.033

9. H. Y. Tran, G. Greco, C. Taubert, M. Wohlfahrt-Mehrens, W. Haselrieder and A. Kwade, Journal of Power Sources, 210, 276(2012), DOI:10.1016/j.jpowsour.2012.03.017

10. M. Stein IV, A. Mistry and P. P. Mukherjee, Journal of the Electrochemical Society, 164, 1616(2017), DOI:10.1149/2.1271707jes

11. N. Kanhere, K. Rafiz, G. Sharma, Z. Sun, Y. Jin and Y. S. Lin, Powder Technology., 353, 230(2019), DOI:10.1016/j.powtec.2019.05.007

12. K. Bachtin, M. Kaus, L. Pfaffmann, S. Indris, M. Knapp, Ch. Roth and H. Ehrenberg, Materials Science and Engineering B, 213, 98(2016), DOI:10.1016/j.mseb.2016.04.006

13. Ai-min Wang and Ni Bai, Solid State Ionics, 336, 19(2019), DOI:10.1016/j.ssi.2019.03.013

14. X. Zhang, J. Hao, L. Wu, Zh. Guo, Zh. Ji, J. Luo, C. Chen, J. Shu, H. Long, F. Yang and A. A. Volinsky, Electrochimica Acta, 283, 1203(2018), DOI:10.1016/j.electacta.2018.07.057

15. Y. Gao, Z. Shang, X. He, T. White, J. Park and X. Liang, Electrochimica Acta, 318, 513(2019), DOI: $10.1016 /$ j.electacta.2019.06.042

16. G. Inoue and M. Kawase, Journal of Power Sources, 342, 478(2017), DOI: $10.1016 /$ j.jpowsour.2016.12.098

17. M. Ebner, Ding-Wen Chung, R.E. García and V. Wood, Advanced Energy Materials, 4, 1301278(2014), DOI:10.1002/aenm.201301278

18. H. Zong, X. Xia, Y. Liang, S. Dai, Ah. Alsaedi, T. Hayat, F. Kong and J. H. Pan, Materials Science and Engineering C, 92, 1075(2018), DOI:10.1016/j.msec.2017.11.007

19. F. Mokhtari, M. Latifi and M. Shamshirsaz, The Journal of The Textile Institute, 107, 1037(2015), DOI: $10.1080 / 00405000.2015 .1083300$

20. J. Pelipenko, J. Kristl, B. Jankovi, S. Baumgartner and P. Kocbek, International Journal of Pharmaceutics, 456, 125(2013), DOI:10.1016/j.jpharm.2013.07.078

21. A. Jaworek and A. T. Sobczyk, Journal of Electrostatics, 66, 197(2008), DOI: $10.1016 /$ j.elstat.2007.10.001

22. F. Huang, Q. Wei, J. Wang, Y. Cai and Y. Huang, e-Polymers, 8, 1618(2008), DOI: 10.1515/epoly.2008.8.1.1758

23. O. Toprakci, A. K. Hatice Toprakci, L. Ji, G. Xu, Zh. Lin and X. Zhang, Applied Material and Interfaces, 4, 1273(2012), DOI:10.1021/am201527r

24. G.-H. An, D.-Y. Lee and H.-J. Ahn, Applied Material and Interfaces, 8, 19466(2016), DOI:10.1021/acsami.6b05307

25. Ch. Kim, S. H. Kang, H. J. Jeon and J. T. Son, Journal of Electroceramics, 31, 204(2016), DOI: $10.1007 / \mathrm{s} 10832-013-9814-\mathrm{Z}$

26. H. Zhou, X. Ding, G. Liu, Y. Jiang, Zh. Yin and X. Wang, Electrochimica Acta, 152, 274(2015), DOI: $10.1016 /$ j.electacta.2014.11.147

27. J.-M. Kim, J. A. Kim, S.-H. Kim, I. Uhm, S. Kang, G. Kim, S.-Y. Lee, S.-H. Yeon and S.-Y. Lee, Advanced Energy Materials, 77, 22(2017), DOI:10.1002/aenm.201701099

28. J. Liu, W. Liu, Sh. Ji, Y. Zhou, P. Hodgson and Y. Li, ChemPlusChem., 8, 605(2013), DOI: $10.1002 /$ cplu.201300180 
RASĀYAN J. Chem.

Vol. 13 | No. 3 |1598-1605| July - September | 2020

29. M. Li, L. Sun, K. Sun, Sh. Yu, R. Wang and H. Xie, Journal of Solid-State Electrochemistry, 16, 3581(2012), DOI: 10.1007/s10008-012-1790-8

30. H.-G. Wang, Y. Zhou, Y. Shen, Y. Li, Q. Zuo and Q. Duan, Electrochimica Acta, 158, 105(2015), DOI: 10.1016/j.electacta.2015.01.149

31. M. Sharma, V. Srinivas, G. Madras and S. Bose, RSC Advances, 6, 6251(2016), DOI:10.1039/C5RA25671B

32. G. H. Tabhane, S. M. Giripunje and S. B. Kondawar, Physica B: Condensed Matter, 571, 149(2019), DOI: 10.1016/j.physb.2019.06.064

33. X. Wang, H. Zhu, G. W. Greene, J. Li, N. Iranipour, C. Garnier, J. Fang, M. Armand, M. Forsyth, J. M. Pringle and P. C. Howlett, Journal of Materials Chemistry A, 4, 9873(2016), DOI: $10.1039 /$ C6TA02817A

34. H. Sun, X. Zhang, Y. He, D. Zhang, X. Feng, Y. Zhao and L. Chen, Chemical Engineering Science, 209, 115186(2019), DOI:10.1016/j.ces.2019.115186

35. N. Ma, J. Cao, H. Li, Y. Zhang, H. Wang and J. Meng, Polymer, 167, 1(2019), DOI: 10.1016/j.polymer.2019.01.053

36. L. Ruan, X. Yao, Y. Chang, L. Zhou, G. Qin and X. Zhang, Polymers (Basel, Switz.), 10, 228(2018), DOI: $10.3390 /$ polym 10030228

37. D. A. Gopakumar, V. Arumukhan, R. V. Gelamo, D. Pasquini, L. C. de Morais, S. Rizal, D. Hermawan, A. Nzihou and H.P.S Abdul Khalil, Nano-Structures \& Nano-Objects, 18, 100268(2019), DOI: $10.1016 / \mathrm{j}$. nanoso.2019.100268

38. M. Hirschler, European Polymer Journal, 18, 463(1982), DOI:10.1016/0014-3057(82)90184-7

39. Y. Li, J. Wang, J. Yao, H. X. Huang, Zh. Q. Du, H. Gu and Zh. T. Wang, Materials Chemistry and Physics, 224, 293(2019), DOI:10.1016/j.matchemphys.2018.12.042

[RJC-5679/2020] 